University of Nebraska - Lincoln

DigitalCommons@University of Nebraska - Lincoln

Faculty Publications: Department of

Entomology

Entomology, Department of

December 2002

\title{
Diagnostic Assays Based on Esterase-Mediated Resistance Mechanisms in Western Corn Rootworms (Coleoptera: Chrysomelidae)
}

\author{
Xuguo Zhou \\ University of Nebraska-Lincoln \\ Michael E. Scharf \\ University of Nebraska-Lincoln \\ Srinivas Parimi \\ University of Nebraska-Lincoln \\ Lance J. Meinke \\ University of Nebraska-Lincoln, Imeinke1@unl.edu \\ Robert J. Wright \\ University of Nebraska-Lincoln, rwright2@unl.edu
}

See next page for additional authors

Follow this and additional works at: https://digitalcommons.unl.edu/entomologyfacpub

Part of the Entomology Commons

Zhou, Xuguo; Scharf, Michael E.; Parimi, Srinivas; Meinke, Lance J.; Wright, Robert J.; Chandler, Laurence D.; and Siegfried, Blair D., "Diagnostic Assays Based on Esterase-Mediated Resistance Mechanisms in Western Corn Rootworms (Coleoptera: Chrysomelidae)" (2002). Faculty Publications: Department of Entomology. 39.

https://digitalcommons.unl.edu/entomologyfacpub/39

This Article is brought to you for free and open access by the Entomology, Department of at DigitalCommons@University of Nebraska - Lincoln. It has been accepted for inclusion in Faculty Publications: Department of Entomology by an authorized administrator of DigitalCommons@University of Nebraska - Lincoln. 


\section{Authors}

Xuguo Zhou, Michael E. Scharf, Srinivas Parimi, Lance J. Meinke, Robert J. Wright, Laurence D. Chandler, and Blair D. Siegfried 


\section{Diagnostic Assays Based on Esterase-Mediated Resistance Mechanisms in Western Corn Rootworms (Coleoptera: Chrysomelidae)}

Xuguo Zhou, Michael E. Scharf, Srinivas Parimi, Lance J. Meinke, Robert J. Wright, Laurence D. Chandler, and Blair D. Siegfried

Journal of Economic Entomology

Volume 95, Issue 6 (December 2002) pp. 1261-1266

DOI: 10.1603/0022-0493(2002)095[1261:DABOEM]2.0.CO;2

Authors may post electronic reprints of their own journal articles after an embargo period of two years has passed from the date of publication. Also, authors must include on the electronic reprint the following statement:

This article is the copyright property of the Entomological Society of America and may not be used for any commercial or other private purpose without specific written permission of the Entomological Society of America. 


\title{
Diagnostic Assays Based on Esterase-Mediated Resistance Mechanisms in Western Corn Rootworms (Coleoptera: Chrysomelidae)
}

\author{
XUGUO ZHOU, MICHAEL E. SCHARF, ${ }^{1}$ SRINIVAS PARIMI, LANCE J. MEINKE, \\ ROBERT J. WRIGHT, ${ }^{2}$ LAURENCE D. CHANDLER, ${ }^{3}$ AND BLAIR D. SIEGFRIED ${ }^{4}$
}

Department of Entomology, University of Nebraska, Lincoln, NE 68583

J. Econ. Entomol. 95(6): 1261-1266 (2002)

\begin{abstract}
Resistance to methyl-parathion among Nebraska western corn rootworm, Diabrotica virgifera virgifera LeConte, populations is associated with increased hydrolytic metabolism of an organophosphate insecticide substrate. An electrophoretic method to identify resistant individuals based on the staining intensity of esterase isozymes on nondenaturing polyacrylamide gels was developed. Three groups of esterases (I, II, and III) were visible on the gels, but only group II esterase isozymes were intensified in resistant populations. A total of 26 and 31 field populations of western corn rootworms from Nebraska (in 1998 and 1999, respectively) were assessed with nondenaturing polyacrylamide gel electrophoresis (PAGE) assays and diagnostic concentration bioassays. Significant correlations were observed between the two diagnostic assays. Group II esterase isozymes provide a reliable biochemical marker for detection of methyl-parathion resistance in individual western corn rootworms and a tool for monitoring the frequency of resistant individuals in field populations.
\end{abstract}

KEY WORDS esterase, insecticide resistance, biochemical marker, Diabrotica virgifera virgifera

THE WESTERN CORN rootworm, Diabrotica virgifera virgifera LeConte, is one of the most serious insect pests of corn, Zea mays (L.), in the Midwestern United States. Most of the economic loss attributed to this species is caused by larval injury to corn roots (Davis 1994, Gray and Steffey 1998, Urias-Lopez and Meinke 2001). Combined crop losses and management costs from Diabrotica species have been estimated to exceed US $\$ 1$ billion annually (Metcalf 1986).

Two chemical control strategies have been implemented to manage $D$. v. virgifera populations in continuous corn. Soil insecticides can be applied at planting time or first cultivation to reduce larval densities and protect roots (Mayo and Peters 1978). Aerial application of insecticides can be used to suppress adult rootworm populations and reduce oviposition thereby, decreasing larval densities the following season (Pruess et al. 1974). Chlorinated hydrocarbons were the first insecticides to be used in Nebraska for larval control (Hill et al. 1948). Continuous corn production and repeated use of cyclodiene insecticides, such as aldrin and dieldrin, in the same fields led to control failures by 1960 (Ball and Weekman 1962).

\footnotetext{
${ }^{1}$ Department of Entomology, Purdue University, West Lafayette, IN 47907.

${ }^{2}$ South Central Res. and Extension Center, University of Nebraska, Clay Center, NE 68933.

${ }^{3}$ USDA-ARS, Red River Valley Agricultural Res. Center, Fargo, ND 58105 .

${ }^{4}$ Department of Entomology, University of Nebraska, Lincoln, NE 68583-0816 (e-mail: bsiegfried1@unl.edu).
}

Organophosphate, carbamate, and pyrethroid insecticides have gradually replaced organochlorine insecticides, and have been widely used as soil insecticides across the Corn Belt. In localized areas of southcentral Nebraska, adult management was adopted after the evolution of larval resistance to soil applied cyclodiene insecticides (Meinke 1995). This practice gradually expanded over large geographic areas as the number of aerial applicators and crop consultants increased. Historically, carbaryl formulations were initially used, but were eventually replaced by widespread use of methyl-parathion (especially Penncap-M) in adult management programs (Meinke et al. 1998). By the early 1990s, complaints about product performance had become common, especially in areas where beetle spraying was used consistently for multiple years (Wright et al. 1996, Meinke et al. 1998). Field surveys of adult susceptibility conducted from 1994-1995 confirmed that adult D. $v$. virgifera evolved a significant level of resistance to methyl-parathion and carbaryl in areas where adult management was the dominant control strategy for multiple growing seasons (Meinke et al. 1998).

In vivo metabolism experiments and in vitro enzyme activity assays indicated that the combined effects of oxidative and hydrolytic metabolisms in certain populations mediated $D$. v. virgifera resistance. Increased hydrolytic metabolism was observed in all populations examined (Miota et al. 1998, and Zhou and Siegfried, unpublished data). Synergism studies using the esterase inhibitor S,S,S-tributyl phosphorotrithio- 

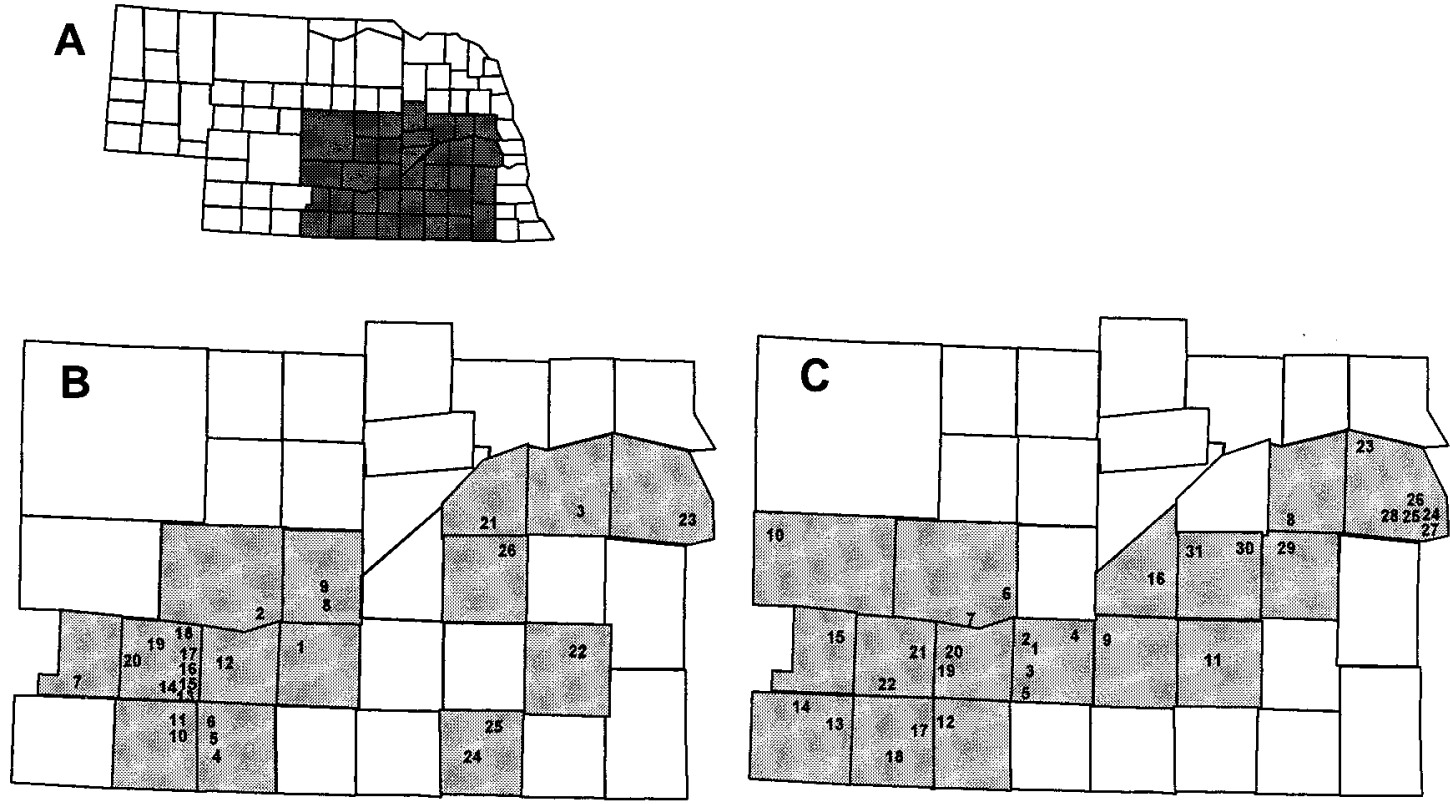

1998

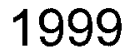

Fig. 1. D. v. virgifera collection sites across Nebraska in 1998 and 1999. The shaded area in the Nebraska State map (A) is enlarged below to show specific collection sites (designated by numerical numbers) within the shaded counties for 1998 (B) and 1999 (C). Each number represents a specific collection site within each year.

ate $(\mathrm{DEF})$ further revealed a common involvement of esterase in both methyl-parathion (Miota et al. 1998) and carbaryl resistance (Scharf et al. 1999, 1999b).

Reliable detection of insecticide resistance is a key element of insect resistance management. Historically, conventional bioassays have been the primary diagnostic tools. However, rapid and sensitive biochemical techniques have been adopted to monitor the intensity and frequency of resistance among field populations of certain species (ffrench-Constant and Roush 1991). Model substrates have been used successfully to identify a number of economically important insects with enhanced hydrolytic activity as part of their resistance mechanisms (e.g., Devonshire and Moores 1982, Byrne and Devonshire 1991, Rose et al. 1995).

The objectives of this study were to select a reliable resistance-associated marker in D. v. virgifera and develop a prototype biochemical monitoring technique for quantifying the frequency of resistant individuals among field populations.

\section{Materials and Methods}

D. v. virgifera Populations. Field populations of adult $D$. $v$. virgifera were collected across Nebraska (Fig. 1) during late July and August of 1998 and 1999, respectively. Collection sites were selected to represent the major corn production areas of the state and corresponded to areas previously identified as having variable levels of methyl-parathion susceptibility. All populations were collected before adult-targeted insecticide application had been initiated. Beetles were maintained in the laboratory at ambient temperature on a standard diet of head lettuce, and sweet corn, Zea mays (L.), for 1 to $5 \mathrm{~d}$ before use in the diagnostic concentration bioassays or before being frozen at $-80^{\circ} \mathrm{C}$ for later use in the nondenaturing PAGE assays.

Chemicals. Technical grade methyl-parathion $(99 \%$ AI) was obtained from Chem-Services (West Chester, PA). Electrophoresis reagents were purchased from Bio-Rad Laboratories (Hercules, CA). Protein assay reagents and bovine serum albumin were purchased from Pierce (Rockford, IL). All other chemicals and solvents used were reagent grade or better.

Diagnostic Concentration Bioassays. Methyl-parathion diagnostic bioassays were conducted within 20 $\mathrm{ml}$, insecticide-coated glass scintillation vials (Meinke et al. 1997, Scharf et al. 1999b). Vials were treated with $0.5 \mu \mathrm{g} / \mathrm{vial}$ methyl-parathion in $0.5 \mathrm{ml}$ acetone solution and rolled until dry in a fume hood. This diagnostic concentration was selected based on the doseresponse curves of a representative resistant and susceptible population and falls within the susceptible $\mathrm{LC}_{99} 95 \% \mathrm{CI}$ at 4 -h exposure. The diagnostic concentration kills $100 \%$ of beetles bioassayed from very susceptible field populations and $<5 \%$ of beetles from the most resistant Nebraska populations. We used 10 replicate vials for each population. Insects were immobilized on ice, and 10 unsexed adults were placed in 

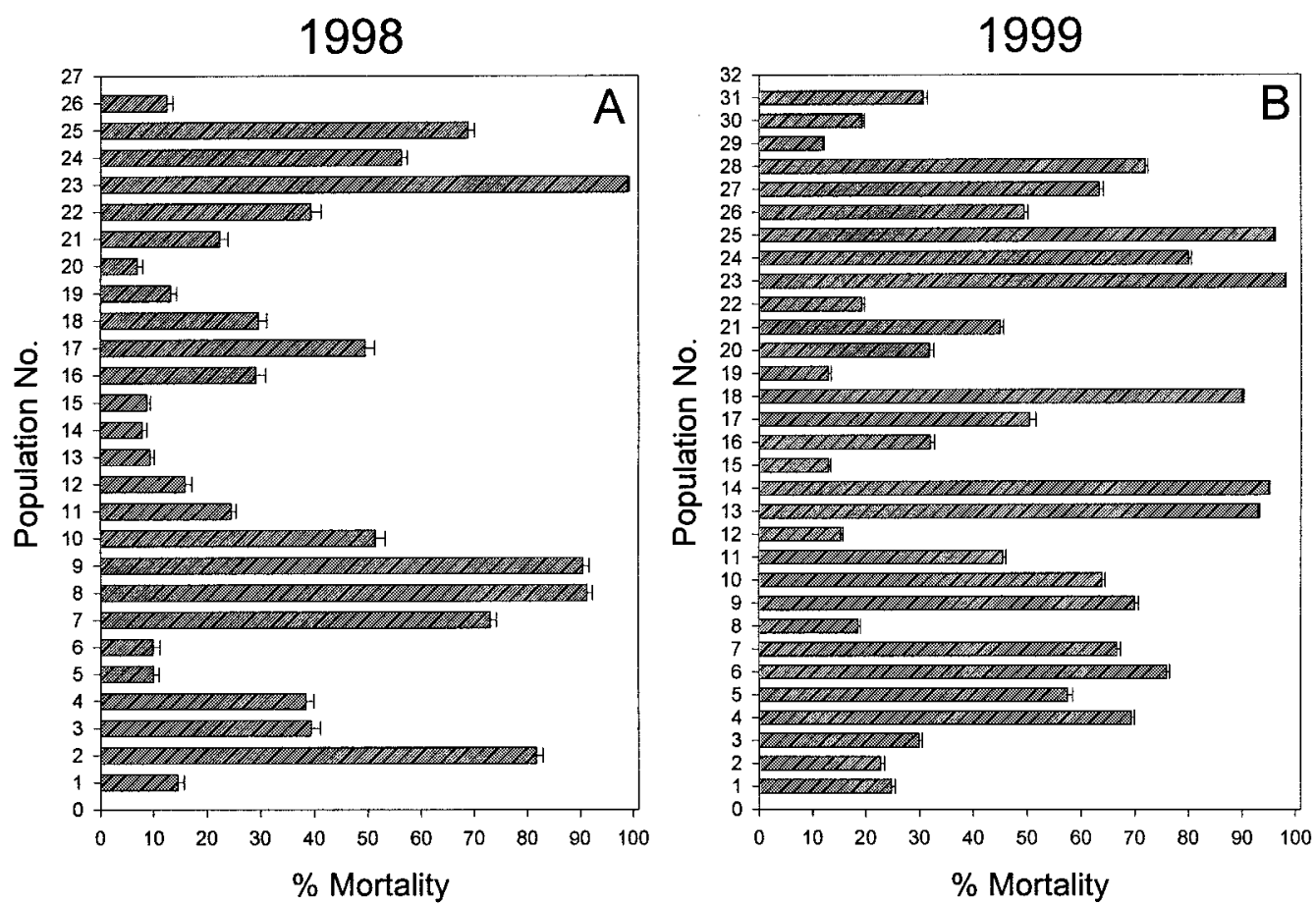

Fig. 2. Methyl-parathion diagnostic concentration bioassay results from 1998 (A) and 1999 (B). Within each year, population numbers correspond to collection sites presented in Fig. 1.

each vial. Vials were held at $22^{\circ} \mathrm{C}$ for $4 \mathrm{~h}$ and mortality was assessed as the inability to move when agitated.

Esterase Enzyme Preparations. Mass homogenates. Abdomens of 10 adult rootworms were homogenized in $0.5 \mathrm{ml}$ ice-cold $0.1 \mathrm{M}$ sodium phosphate buffer $(\mathrm{pH}$ $7.8,0.1 \%$ Triton X-100) with a Potter-Elvehjem homogenizer. The homogenate was centrifuged at $10,000 \times g$ and $4^{\circ} \mathrm{C}$ for $20 \mathrm{~min}$. The resulting $10,000 \times$ $g$ supernatant was ultracentrifuged at $100,000 \times g$ and $4^{\circ} \mathrm{C}$ for $60 \mathrm{~min}$. The $100,000 \times g$ supernatant was used as the enzyme source and was held on ice before electrophoresis.

Single beetle homogenates. Forty-eight adult abdomens were placed individually into the wells of a 96-well flat bottom microplate (353912 FALCON, Biosciences Discovery Labware, Franklin Lakes, NJ) containing $100 \mu \mathrm{l}$ ice-cold homogenization buffer. Abdomens were homogenized by a combination of vertical and circular movement with a 96-spoke inoculating manifold (MC96, Dan-Kar, Reading, MA) for $30 \mathrm{~s}$. The homogenate $(10 \mu \mathrm{l})$ from each beetle was then transferred with a multi-channel pipettor to a new microplate and stored on the ice for subsequent nondenaturing PAGE assays.

Single Beetle Nondenaturing PAGE Assays. Nondenaturing PAGE assays were carried out in a vertical electrophoresis apparatus (Bio-Rad Mini Protean II, Richmond, CA) using a $7.5 \%$ separating gel and $4 \%$ stacking gel with a continuous Tris-glycine running buffer system $(50 \mathrm{mM}, \mathrm{pH}$ 8.3). Samples $(10 \mu \mathrm{l})$ of individual beetle homogenates were diluted 1:1 with
$2 \times$ sample buffer [ $20 \%$ sucrose (wt:vol), $0.1 \%$ bromophenol blue in $50 \mathrm{mM}$ Tris-glycine running buffer ( $\mathrm{pH}$ 8.3) ] before loading. Gels were run at $120 \mathrm{~V}$ constant voltage for $75 \mathrm{~min}$ at $4^{\circ} \mathrm{C}$. Esterase bands were visualized by incubating the gels in $100 \mathrm{ml} 0.02 \mathrm{M}$ sodium phosphate buffer ( $\mathrm{pH} 7.0$ ) with $2 \%$ (by volume) $30 \mathrm{mM} \beta$-naphthyl acetate dissolved in acetone at $30^{\circ} \mathrm{C}$ for 15 min before adding $0.04 \%$ fast blue BN salt (tetrazotized O-dianisidine) (wt/vol). After staining, the PAGE gels were examined for the presence or absence of group II esterase isozymes.

Protein and Esterase Activity Assays. Protein concentration was determined with the bicinchoninic acid protein assay kit (Pierce, Rockford, IL) using bovine serum albumin as the standard. General esterase activity was assayed by colorimetric measurement of $\beta$-naphthol formation. For these assays, the approach of van Asperen (1962) was adapted to a 96-well microplate format.

Statistical Analyses. All regression analyses were determined by SAS PROC REG (SAS Institute 2001).

\section{Results}

Diagnostic Concentration Bioassays. Collection sites of the D. v. virgifera field populations used in the 1998 and 1999 diagnostic assays are identified in Fig. 1. Collection sites ranged from south central to east central Nebraska, and extended over an area of $\approx 41,600$ $\mathrm{km}^{2}$. The selected populations represented a wide range of methyl-parathion susceptibility (Fig. 2). The 


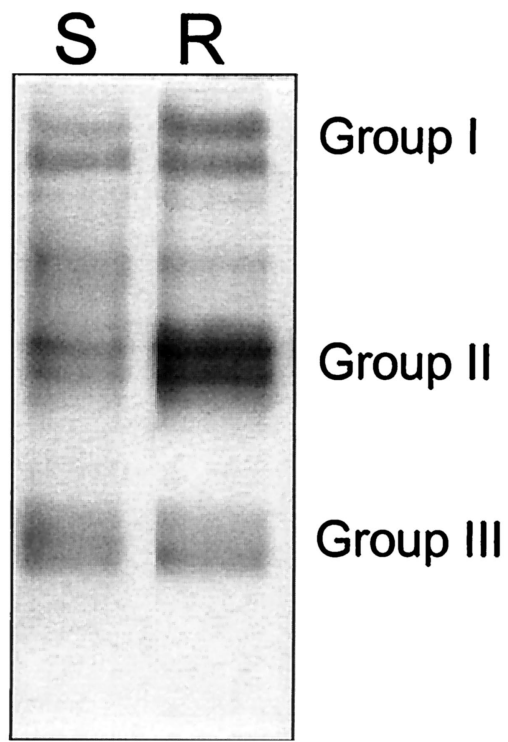

Fig. 3. Comparison of esterase isozymes between susceptible and resistant $D$. v. virgifera field populations separated by nondenaturing PAGE (S, susceptible population; $R$, resistant population).

percentage mortalities observed at the diagnostic concentration ranged from $7.0 \%$ (highly resistant population) to $99.0 \%$ (highly susceptible), with a generally continuous distribution of mortality in between.

Nondenaturing PAGE Assays. Mass homogenates. Three distinct esterase isozyme groups (designated as group I, II, and III) were clearly visible in the nondenaturing PAGE gels (Fig. 3) of both resistant and susceptible D. v. virgifera strains. However, the group II esterase isozymes from resistant populations showed consistently higher staining intensity relative to susceptible populations. Similar gel patterns of es- terase isozymes from resistant and susceptible western corn rootworms were reported by Miota et al. (1998) and Scharf et al. (1999a).

There was no relationship between protein concentrations and general esterase activities in individual beetles $\left(r^{2}=0.008, P=0.76, n=14\right.$, in resistant population; $r^{2}=0.070, P=0.46, n=10$, in susceptible population). Therefore, staining intensity should not be influenced by slight differences in total protein concentration among individual beetle homogenates, and it was determined that standardization of protein concentration was not necessary for the single beetle nondenaturing PAGE assays.

Single Beetle Assays. The group II esterase isozymes were clearly identified from homogenates of individual rootworm abdomens in resistant populations, but were almost undetectable in susceptible populations (Fig. 4). In 1998 and 1999, susceptibility as determined by diagnostic concentration bioassays explained 90 and $92 \%$, respectively, of the variability in elevated group II esterase isozymes determined by nondenaturing PAGE (Fig. 5). These results provide further support for the involvement of hydrolytic enzymes in the mechanism of resistance to methyl-parathion.

\section{Discussion}

Results from this investigation indicate existence of a range of methyl-parathion susceptibilities among western corn rootworm populations in Nebraska. Susceptibility is highly correlated with specific activity patterns of general esterase isozymes. Three esterase isozyme groups are visible on nondenaturing polyacrylamide gels. Of these, group II esterases in resistant populations showed elevated activity toward the model substrate, $\beta$-naphthyl acetate.

Because of the esterase polymorphism in insects, electrophoresis provides a useful tool to categorize individual insects as resistant or susceptible. Nonde-

\section{Population \# 23 (99.0\% mortality)}
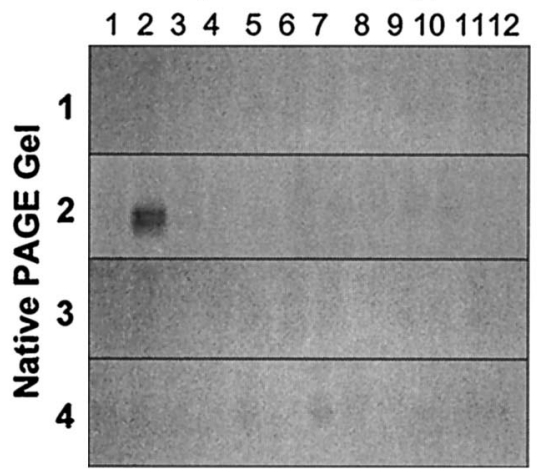

Population \# 25 ( $68.9 \%$ mortality)
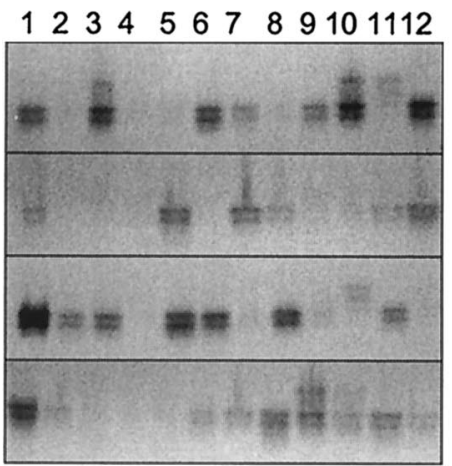

Population \# 14 ( $8.0 \%$ mortality)
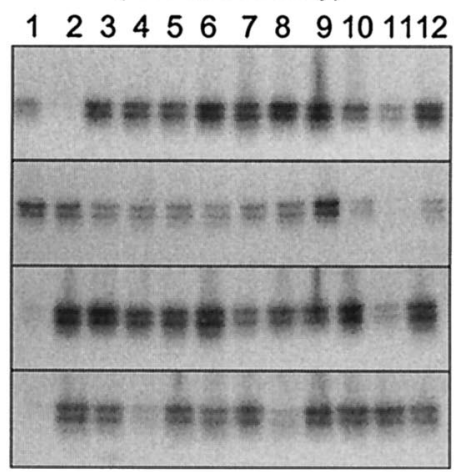

Fig. 4. Single beetle nondenaturing PAGE assays from three representative populations of the 1998 field survey with high (\#23; 99\% mortality), intermediate (\#25; 68\% mortality), and low (\#14; $8 \%$ mortality) levels of susceptibility to methylparathion based on diagnostic concentration bioassay results. Number 1-4 (positioned vertically along gels) represents four separate gels per population. Numbers positioned horizontally above gels represents 12 beetles (one per lane) per gel $(n=$ 48 beetles per population). 


\section{8}

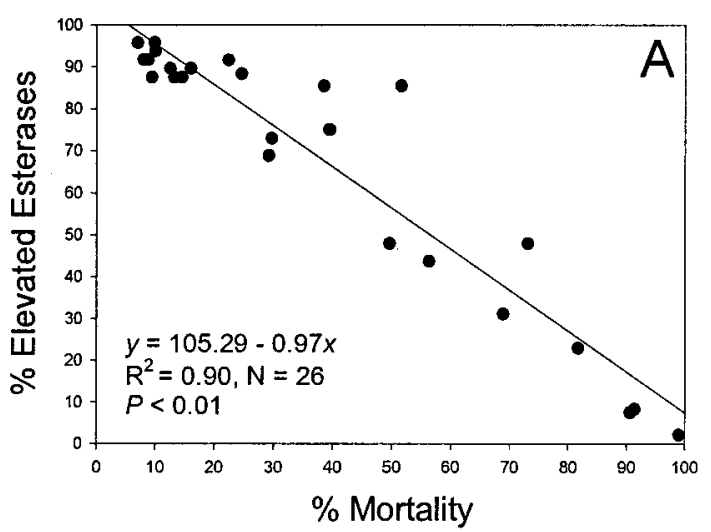

1999

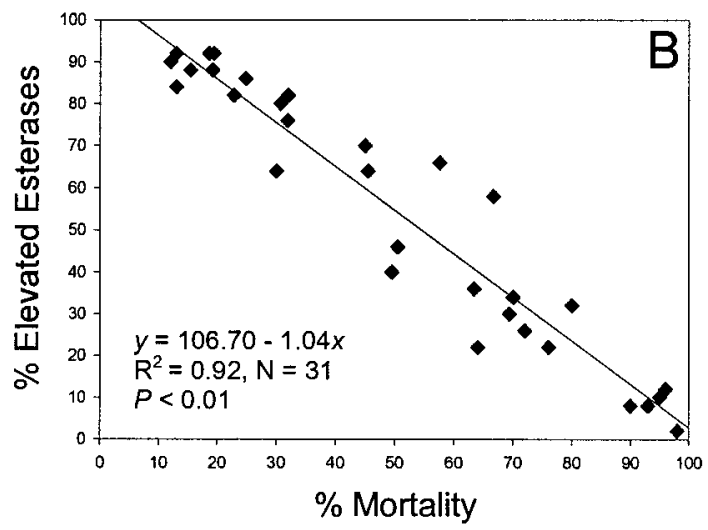

Fig. 5. Relationship and linear regression between D. v. virgifera mortality determined by the methyl-parathion diagnostic concentration bioassays and the frequency of elevated esterase isozymes estimated by the single beetle nondenaturing PAGE assays conducted in 1998 (A) and 1999 (B). Each point represents one of the 26 and 31 (respectively) populations that are shown in Fig. 2.

naturing PAGE detection of esterase isozymes associated with insecticide resistance has been used extensively as a diagnostic tool. For example, elevated esterase banding patterns have been found in resistant populations of Schizaphis graminum (Rondani) (Shufran et al. 1996, 1997), Myzus persicae Sulzer (Devonshire 1989), Bemisia tabaci (Genn.) (Byrne and Devonshire 1991, 1993), and Anopheles albimanus Wiedemann (Brogdon and Barber 1990).

The reliability of using electrophoresis for largescale resistance monitoring has been questioned because of the subjectivity of assessing the intensity of esterase bands on the nondenaturing polyacrylamide gels. For example, from 1991 to 1995, $\approx 14,000$ Schizaphis graminum from Kansas, Texas, Oklahoma, and Colorado were examined with nondenaturing PAGE assays. During the process, cost and under-estimation of resistant individuals hindered the ability to effectively monitor the resistance gene frequency in field populations by PAGE (Shufran et al. 1997). In this study, as expected, esterase isozyme patterns from single beetle homogenates were similar to those of mass homogenates, although single beetle gel patterns suggested greater diagnostic potential. When individual D. v. virgifera were homogenized and separated on nondenaturing PAGE gels, only elevated group II esterase isozymes from resistant individuals were clearly visible. This was a substantial improvement over the three-esterase groups observed on the mass homogenate gels. This distinctive esterase pattern from individual beetles made the determination of resistance status more efficient and much more precise.

Nondenaturing PAGE assays cannot only detect the existence of insecticide resistance in this case, but can also estimate the magnitude of resistance ratios. Resistance ratios estimated by the quantitative staining intensity of group II esterase isozymes (Quantity One Quantitation Software, Gel Documentary System, Bio-Rad Laboratories, Hercules, CA) from the resis- tant and susceptible populations were similar to those determined from the specific activity of the esterase (X.G.Z., unpublished data).

Biochemical-based assays, which diagnose both the qualitative and quantitative differences in detoxification enzymes, significantly improve the speed, accuracy, and sensitivity of resistance monitoring. The main advantage of biochemical resistance assessment methods is the ability to monitor subtle changes in the resistant gene frequency caused by chemical selection, unlike traditional bioassays that measure the average response of a heterogeneous population (Devonshire 1989). Because of the esterase polymorphism observed in D. v. virgifera and the distinctive gel pattern toward model substrates exhibited by the resistant individuals on the nondenaturing PAGE gels, group II esterase isozymes are a legitimate biochemical marker for identifying resistant individuals directly from the field. Based on the 1998 and 1999 assay results, the single beetle nondenaturing PAGE technique was highly comparable to the conventional diagnostic concentration bioassay, and further established itself as a biochemical diagnostic tool for monitoring the frequency of resistance-associated esterase genes in field populations.

\section{Acknowledgments}

We thank Tim Nowatzki and David Taylor for valuable comments on an earlier draft of this manuscript. Jim Brown and Jenny Stebbing helped collect and maintain D. v. virgifera field populations. Support for this project was provided by DuPont, FMC, Zeneca, American Cyanamid, Dow Agrosciences, USDA Specific Cooperative Agreement 58-5447-6116 and USDA IFAFS Grant 00-S2103-9669. This is journal series No. 13672 of the University of Nebraska Agricultural Experiment Station and contribution No 1124 of the Department of Entomology. 


\section{References Cited}

Ball, H. J., and G. T. Weekman. 1962. Insecticide resistance in the western corn rootworm in Nebraska. J. Econ. Entomol. 55: 439-441.

Brogdon, W. G., and A. M. Barber. 1990. Fenitrothion-deltamethrin cross-resistance conferred by esterases in Guatemalan Anopheles albimanus. Pestic. Biochem. Physiol. 37: 130-139.

Byrne, F. J., and A. L. Devonshire. 1991. In vivo inhibition of esterase and acetylcholinesterase activities by profenofos treatments in the tobacco whitefly Bemisia tabaci (Genn.): implications for routine biochemical monitoring of these enzymes. Pestic. Biochem. Physiol. 40: 198204.

Byrne, F. J., and A. L. Devonshire. 1993. Insensitive acetylcholinesterase and esterase polymorphism in susceptible and resistant populations of the tobacco whitefly Bemisia tabaci (Genn.). Pestic. Biochem. Physiol. 45: 34-42.

Davis, P. M. 1994. Comparison of economic injury levels for western corn rootworm (Coleoptera: Chrysomelidae) infesting silage and grain corn. J. Econ. Entomol. 87: 10861090.

Devonshire, A. L., and G. D. Moores. 1982. A carboxylesterase with broad substrate specificity causes organophosphorus, carbamate, and pyrethroid resistance in peach-potato aphids (Myzus persicae). Pestic. Biochem. Physiol. 18: 235-246.

Devonshire, A. L. 1989. The role of electrophoresis in the biochemical detection of insecticide resistance. $\operatorname{In} \mathrm{D}$. L. Hugh and J. D. Hollander [eds.], The Systematics Association special volume. Electrophoretic studies on agricultural pests, vol. 39. Oxford University Press, New York.

ffrench-Constant, R. H., and R. T. Roush. 1991. Gene mapping and cross-resistance in cyclodiene insecticide-resistant Drosophila melanogaster (Meigen). Genetical Res. 57: 17-22.

Gray, M. E., and K. L. Steffey. 1998. Corn rootworm (Coleoptera: Chrysomelidae) larval injury and root compensation of 12 maize hybrids: an assessment of the economic injury index. J. Econ. Entomol. 91: 723-740.

Hill, R. E., E. Hixson, and M. H. Muma. 1948. Corn rootworm control tests with benzene hexachloride, DDT, nitrogen fertilizers, and crop rotations. J. Econ. Entomol. 41: 392-401

Mayo, Z. B., and L. L. Peters. 1978. Planting vs cultivation time applications of granular soil insecticides to control larvae of corn rootworms in Nebraska. J. Econ. Entomol. 71: 801-803.

Meinke, L. J. 1995. Adult corn rootworm management. Univ. Neb. Agric. Res. Div. Misc. Publ. 63.

Meinke, L. J., B. D. Siegfried, R. J. Wright, and L. D. Chandler. 1997. Western corn rootworm resistance to insecticides: current situation in Nebraska. Proc. Illinois Agric. Pesticides Conf. 88-92.

Meinke, L. J., B. D. Siegfried, R. J. Wright, and L. D. Chandler. 1998. Adult susceptibility of Nebraska western corn rootworm (Coleoptera: Chrysomelidae) populations to selected insecticides. J. Econ. Entomol. 91: 594600.

Metcalf, R. L. 1986. Foreword. In: J. L. Krysan and T. A Smith [eds.], Methods for the study of pest Diabrotica. New York: Springer.

Miota, F., M. E. Scharf, M. Ono, P. Marcon, L. J. Meinke, R. J. Wright, L. D. Chandler, and B. D. Siegfried. 1998. Mechanisms of organophosphate resistance in the western corn rootworm (Coleoptera: Chrysomelidae). Pestic. Biochem. Physiol. 61: 39-52.

Pruess, K. P., J. F. Witkowski, and E. S. Raun. 1974. Population suppression of western corn rootworm by adult control with ULV malathion. J. Econ. Entomol. 67: 651655.

Rose, R. L., L. Barbhaiya, R. M. Roe, G. C. Rock, and E. Hodgson. 1995. Cytochrome, p. 450-associated insecticide resistance and the development of biochemical diagnostic assays in Heliothis virescens. Pestic. Biochem. Physiol. 51: 178-191.

SAS Institute. 2001. SAS user's guide: Statistics, version 8.2. SAS Institute, Cary, NC.

Scharf, M. E., L. J. Meinke, R. J. Wright, L. D. Chandler, and B. D. Siegfried. 1999a. Metabolism of carbaryl by insecticide-resistant and -susceptible western corn rootworm populations (Coleoptera: Chrysomelidae). Pestic. Biochem. Physiol. 63: 85-96.

Scharf, M. E., L. J. Meinke, B. D. Siegfried, R. J. Wright, and L. D. Chandler. 1999b. Carbaryl susceptibility, diagnostic concentration determination, and synergism for U.S. populations of western corn rootworm (Coleoptera: Chrysomelidae). J. Econ. Entomol. 92: 33-39.

Shufran, R. A., G. E. Wilde, and P. E. Sloderbeck. 1996. Description of three isozyme polymorphisms associated with insecticide resistance in greenbug (Homoptera: Aphididae) populations. J. Econ. Entomol. 89: 46-50.

Shufran, R. A., G. E. Wilde, P. E. Sloderbeck, and W. P. Morrison. 1997. Occurrence of insecticide resistant greenbugs (Homoptera: Aphididae) in Kansas, Texas, Oklahoma, and Colorado and suggestions for management. J. Econ. Entomol. 90: 1106-1116.

Urias-Lopez, A. M., and L. J. Meinke. 2001. Influence of western corn rootworm (Coleoptera: Chrysomelidae) larval injury on yield of different types of maize. J. Econ. Entomol. 94: 106-111.

van Asperen, K. 1962. A study of housefly esterases by means of a sensitive colorimetric method. J. Insect Physiol. 8: 401-416.

Wright, R. J., L. J. Meinke, and B. D. Siegfried. 1996. Corn rootworm management and insecticide resistance management, pp. 45-53. In Proceedings 1996 Crop Protection Clinics. University of Nebraska Cooperative Extension, Lincoln, NE.

Received for publication 3 April 2002; accepted 1 August 2002. 